\title{
Comparison of resin composite restorations microleakage: An in-vitro study
}

\author{
Horieh Moosavi $^{1}$, Fatemeh Maleknejad Yazdi $^{1}$, Fatemeh Velayati Moghadam ${ }^{1}{ }^{*}$, Saherh Soltani ${ }^{2}$ \\ ${ }^{1}$ Dental Material Research Center and Operative Dentistry Department, Dental School, Mashhad University of Medical Sciences, \\ Mashhad, Iran \\ ${ }^{2}$ Dentist, Mashhad, Iran \\ Email: $\underline{\text { Velayatimf@mums.ac.ir }}$
}

Received 8 March 2013; revised 25 April 2013; accepted 8 May 2013

Copyright (C) 2013 Horieh Moosavi et al. This is an open access article distributed under the Creative Commons Attribution License, which permits unrestricted use, distribution, and reproduction in any medium, provided the original work is properly cited.

\begin{abstract}
The aim of this study was to compare the microleakage of total-etch and self-etch adhesives by three methods including dye extraction, dye penetration and fluid filtration with determining the correlation value among these techniques. Seventy-two premolar teeth were selected for this in vitro study and Class 5 cavities were prepared on the buccal surface of these at the cemento-enamel junction area. It was applied for half of these cavities, Optibond Solo Plus (OSP) (twostep etch \& rinse) and another half, Optibond All-inOne (OA) (one-step self-etch) and then all of them were restored with a light cure resin composite; Herculite XRV. Then samples were divided randomly into three subgroups based on the method of microleakage measurement $(n=12)$. In the first pair group, leakage was assessed by the dye extraction method. Dye penetration and fluid filtration methods were used in the second and third pair groups for the same purpose respectively. Data were analyzed by Paired t-test and Wilcoxon test and correlation coefficients $(\alpha=0.05)$. There was no significant difference in the dye extraction $(P=0.657)$ and dye penetration $(P=$ 0.732 ) methods between the microleakage of totaletch and self-etch adhesives. Microleakage of self-etch adhesive in fluid filtration technique was significantly more than total-etch adhesive $(P=\mathbf{0 . 0 1 2})$. No significant correlation was found among the results obtained with the three methods of microleakage evaluation. Adhesive systems showed variously behave in different methods of microleakage assessment.
\end{abstract}

Keywords: Dye Extraction; Dye Penetration; Fluid Filtration; Microleakage

"Corresponding author.

\section{INTRODUCTION}

One of the esthetic materials which are used for restoration of Class V caries lesions is a resin composite with various dentine bonding systems which adhering the resin composite to tooth [1]. An important factor in the success of the RC restorations is the properties of adhesive bonding agents. Resin-based adhesive systems can be classified in either the etch-and-rinse (ER) systems or the self-etch (SE) systems. The disadvantages of the ER systems are the technique sensitivity and the likely discrepancy between the extent of demineralization and monomer infiltration [2] and subsequent degradation of these adhesives when they are exposed to the mouth environment during passing time $[3,4]$. The key advantages of SE adhesives are their easy and fast application procedures [5]. This approach significantly reduces technical sensitivity. Infiltration of adhesive occurs simultaneously with the etch process; therefore the discrepancy between both processes is low and less time consuming [6, 7]. Knowing the success and longevity of various adhesives enables practitioners to choose the most appropriate material for the clinical use. The information on the bonding effectiveness of adhesives in laboratory conditions indicated that the bond strength of the all-in-one systems to enamel and dentin is not as high as other adhesive systems $[8,9]$. The cavity extends below the cementoenamel junction (CEJ) with the margins in dentin; microleakage, gap formation, and inappropriate adhesion to dentin remain considerable problems [10]. The natural structure of dentin such as organic material content, the existence of liquid and odontiblastic branches in dentin, and the formation of the smear layer, are factors preventing acquisition of a strong and durable bond [11,12]. An adhesive restoration may not attach properly to the etched dentineand forming marginal gap and microleakage [13]. Marginal microleakage of restorations and the transmis- 
sion of bacteria, liquids, and molecules between the cavity surface and the restorative material result in hypersensitivity, secondary caries, pulp stimulation, and marginal discoloration [14-17]. There are a lot of studies were done on the microleakage of recent generation of adhesives which generally including Class V composite restorations. Different leakage tracers such as methylene blue, silver nitrate or basic fuchsin were used in these studies and profundity of dye was detected in each sample for resin-dentin interface [18]. In addition to the older methods like fluid filtration and dye penetration, it is necessary to compare other microleakage test like dye extraction for composite resin restorations with them. In this method, methylene blue dilution in nitric acid was assessed by spectrophotometer with wavelength of 550 $\mathrm{nm}$ [19]. Similarly to the previous studies on themicroleakage evaluation of dentine adhesives [19-21], in this study, in addition to the common methods like fluid filtration and dye penetration, it was used dye extraction method and the correlations of these methods were determined. Therefore, the purpose of this study was to compare the microleakage of a total-etchadhesive and a selfetchadhesive of one commercial brand by three methods including fluid filtration, dye penetration and dye extraction, and determining the correlation among three methods.

\section{MATERIALS AND METHODS}

Seventy-two freshly extracted human premolar teeth with no cares, filling, crack and abrasion was selected for this in-vitro study. The teeth were extracted because of periodontal or orthodontic problems and not extended than 3 months from the extraction. After debridement the crown and root of teeth by scaling and root planning instruments, they were stored in $0.1 \%$ thymol solution at $4^{\circ} \mathrm{C}$. The thymol solution was changed to normal saline one week before use. Class V cavities with $3 \mathrm{~mm}$ mesiodistal width, $1.5 \mathrm{~mm}$ axial depth and $2 \mathrm{~mm}$ occluso gingivally length were prepared at the cement-enamel junction on the buccal surface of teeth. The occlusal margin of the cavity was located on the enamel and the gingival margin was located on the cementum. After cleaning the prepared cavities with flour of pumice and prophylactic rubber cup, half of the samples were treated randomly with Opti Bond Solo Plus (Kerr, Orange, USA) a totaletch adhesive and half of them were applied with Opti Bond All-in-One (Kerr, Orange, USA) a self-etch adhesive. Adhesives were used according to the manufacturer's instruction. After application of the adhesive systems, prepared cavities were filled with a micro hybrid light cure resin composite Herculite XRV (Kerr, USA) incrementally in two $0.75 \mathrm{~mm}$ layers and each increment was cured for 20 seconds. The intensity of light curing unit was $800 \mathrm{~mW} / \mathrm{cm}^{2}$. Materials, chemical compositions and clinical application were used in this study listed in Table 1.

After 24 hours, the restorations were finished and polished. The samples of each adhesive was randomly divided into three groups (each 24) based on the method used for measuring the microleakage. Another operator measered the samples microleakage with below protocols:

Dye extraction method: it was used to measure the microleakage in restoration-dentin interface for total-etch and self-etch adhesive subgroups $(\mathrm{n}=24)$. First the samples were covered with $1 \mathrm{~mm}$ of restoration margins with two layers of nail varnish, the apices of roots were sealed with sticky wax and immersed in the $2 \%$ methylene blue solution for 24 hours. After 24 hours, the samples were rinsed under tap water for 30 minutes and nail varnish was removed by polishing disks. Then, for uses of spectrophotometer, the samples were put in vials containing $65 \mathrm{wt} \%$ nitricacid for 3 days to let methylene blue within restorationdentin interface diluted in nitric acid. It is necessary to mention that there was $1000 \mu \mathrm{l}$ acid volume in each vial. The vials were centrifuged $14,000 \mathrm{rpm}$ for 5 minutes and after that, $100 \mu \mathrm{l}$ of the supernatant from each was transferred to a plate. The dye absorption was measured by an automatic spectrophotometer at $550 \mathrm{~nm}$ using concentrated nitric acid as the blank. The results of the spectrophotometer indicate the light absorption of the methylene blue in the resin-dentin interface which is ac-

Table 1. Materials, manufacturers, chemical compositions and clinical applications used in this study.

\begin{tabular}{|c|c|c|c|}
\hline Material name & Manufacturer & Chemical composition & Clinical application \\
\hline $\begin{array}{l}\text { Optibond Solo Plus } \\
\text { adhesive (OSP); Two-step } \\
\text { total-etch adhesive }\end{array}$ & $\begin{array}{l}\text { Kerr Corporation, Orange, } \\
\text { CA, USA }\end{array}$ & $\begin{array}{l}\text { HEMA, Bis GMA, Camphorquinone, Barium } \\
\text { borosilicate, Sodium hexaflurosilicate, Ethanol }\end{array}$ & $\begin{array}{l}35 \% \text { phosphoric acid for } 15 \mathrm{~s} \text {, rinse, } \\
\text { removes excess water. Apply bonding } \\
\text { for } 20 \mathrm{~s} \text {, briefly air-dry, light-activate for } \\
20 \mathrm{~s} \text {. }\end{array}$ \\
\hline $\begin{array}{l}\text { Optibond All-in-One } \\
\text { adhesive (OA); One-step } \\
\text { self-etch adhesive }\end{array}$ & $\begin{array}{l}\text { Kerr Corporation, Orange, } \\
\text { CA, USA }\end{array}$ & $\begin{array}{l}\text { HEMA, GPDM, Camphorquinone, } \\
\text { Co-monomers, Three nanosized fillers, Sodium } \\
\text { hexaflurosilicate, Yttereium fluoride, } \\
\text { Solvent-water, acetone, ethanol }\end{array}$ & $\begin{array}{l}\text { Apply bonding for } 20 \mathrm{~s} \text { in two layers, } \\
\text { gently air-dry, light-activate for } 20 \mathrm{~s} \text {. }\end{array}$ \\
\hline $\begin{array}{l}\text { Herculite XRV composite; } \\
\text { (Micro-hybrid composite) }\end{array}$ & $\begin{array}{l}\text { Kerr Corporation, Orange, } \\
\text { CA, USA }\end{array}$ & $\begin{array}{l}\text { Bis-GMA resin matrix, } 79 \mathrm{wt} \% \text { filler, } \\
\text { Camphorquinone, etc. }\end{array}$ & $\begin{array}{l}\text { Apply incrementally in two layers, each } \\
\text { layer light-activate for } 20 \mathrm{~s} \text {. }\end{array}$ \\
\hline
\end{tabular}


tually showing the microleakage of the restoration.

Dye penetration method: it is used to measure the microleakage as the following way for two used adhesives $(n=24)$. First the samples were sealed like the first group and immersed in $2 \%$ methylene blue solution for 24 hours. After that, the samples were rinsed under tap water for 30 minutes. Then the samples were embedded in Epoxy Resin and restorations sectioned buccolingually through its mesiodistal center by a water-cooled diamond saw. Each section was assessed by a stereomicroscopeat $60 \times$ magnification to measure the microleakage. To measure the microleakage in this study, a scale from 0 to 3 was used. Score $0=$ no marginal leakage, Score $1=$ dye penetration up to $1 / 2$ depth of the cavity, Score $2=$ dye penetration more than $1 / 2$ depth of the cavity and Score 3 $=$ dye penetration extending to the axial wall of the cavity.

Fluid filtration method: it is based on the evaluation of liquid transportation in the specimen, which was calculated from the movement of bubbles. Fluid leaking through the restoration interface of the specimens was measured by displacement of an air bubble in an attached glass capillary. An oxygen tank with a manometer (for precise adjustment of pressure) was attached to set-up. A plastic tube must be connected to the oxygen source, and the end part should be connected to an erlen. A plastic tube was connected to a three-valve tube by a $0.5 \mathrm{~cm} \times 2$ $\mathrm{cm}$ long latex pipe. A syringe was connected to the lower side of the three-valve tube to make an air bubble through the micro pipette. The upper side was connected to the specimens. The cyanoacrylate glue was smeared on all of the system connections (Inter Lock, Japan) and multiple layers of Para film strips were covered all of them (Parafilm "M"; Laboratory film, Chicago, IL). These strips seal the connections in tubes and ensure a strong connection. A diamond disk which was mounted on a low speed hand pice used to sectioning the roots from the crowns to $2 \mathrm{~mm}$ below the cemento-enamel junction (C.E.J). The pulpal soft tissue was removed and the area washed with a saline solution. A plexiglass surface was used as the base of the final crown segments. The camera was zoomed and focused on the macrograph to produce a sharp image. By opening the faucet and removing the syringe, the pass in there was a straight connection between the tooth and the fluid filtration system. The main oxygen tank faucet was opened and remained in a constant, exact pressure ratio during the experiment. Then the digital camera started capturing the steps in every 2 minutes $(2,4,6,8 \mathrm{~min})$. All the process was repeated for the system and all the data were saved to the P.C Hard Disc and the bubble movement was evaluated by the Photoshop software.

Data were analyzed by Paired t-test, Mann-Whitney, Pearson and Spearman tests. All statistical tests were run at $5 \%$ significance level $(\mathrm{P} \leq 0.05)$.

\section{RESULTS}

For comparing the microleakage of total-etch and selfetch adhesives, Figure 1 was indicated that there was more leakage in self-etch adhesive than total-etch adhesive for dye extraction method but using Paired t-test, there was no significant difference in microleakage between the adhesives $(\mathrm{P}=0.728)$.

According to the results illustrating in Figure 2, for dye penetration method the microleakage of total-etch adhesive was more than self-etch adhesive while usingMann-Whitney showed there was no significant difference in the microleakages of the adhesives $(\mathrm{P}=0.755)$.

Figure 3 was illustrated that in fluid filtration method, the microleakage of self-etch adhesive was more than total-etch adhesive and by using Paired t-test, the microleakage of the two adhesives indicated a significant difference $(\mathrm{P}=0.002)$. Therefore, using fluid filtration method to assess the microleakage, Optibond All-in-One (self-etch adhesive) had more leakage than Optibond Solo Plus (total-etch adhesive).

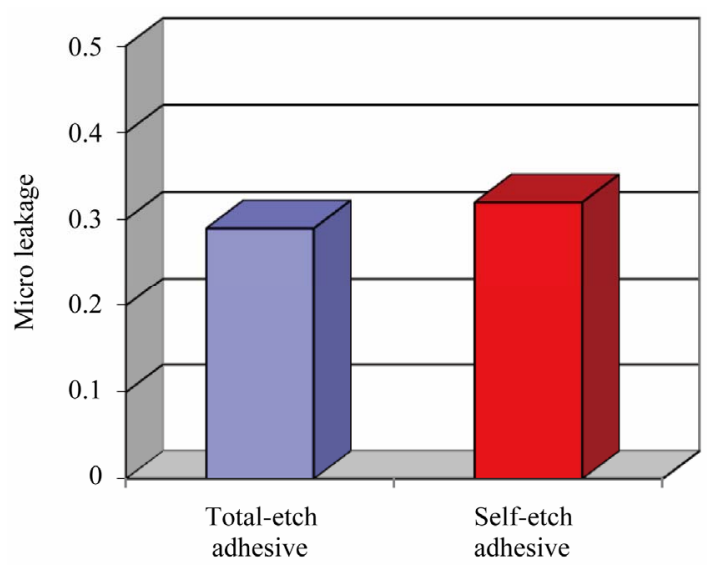

Figure 1. The comparisons of average microleakage in total-etch and self-etch adhesives in dye extraction method.

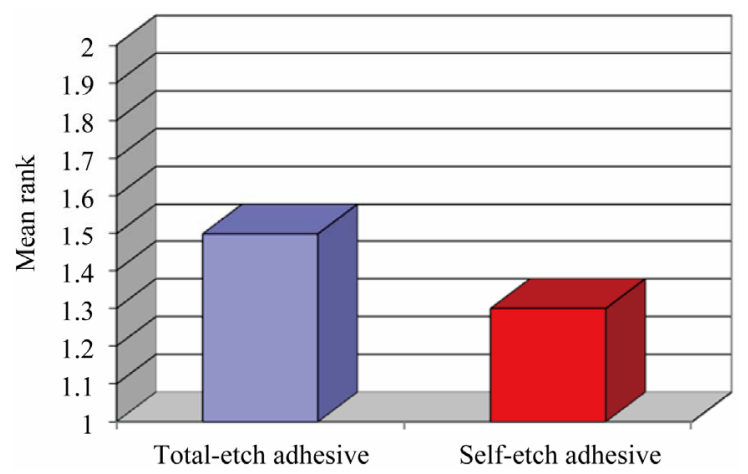

Figure 2. The comparison of average microleakage in total-etchand self-etch adhesives in dye penetration method. 


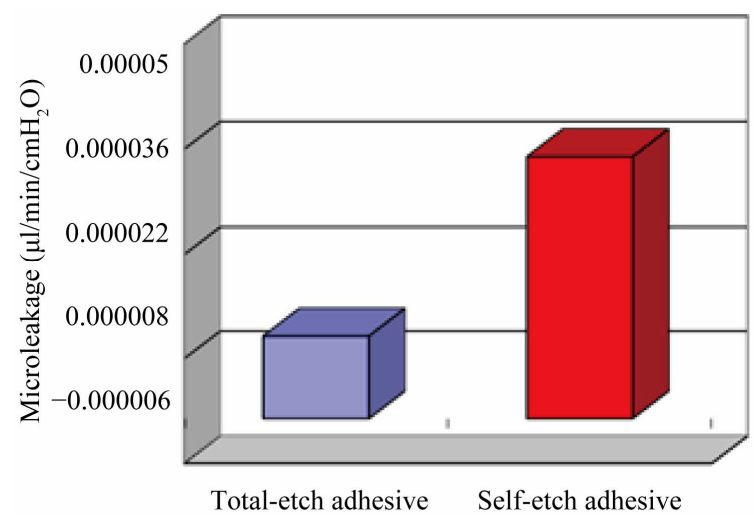

Figure 3. The comparison of average microleakage in total-etchand self-etchadhesives by fluid filtration method.

According to the Table 2 there were no significant correlation between different methods of microleakage measurement, but there was a positive correlation between them.

\section{DISCUSSION}

The main gold of this study was to compare the three methods for microleakage assessment including dye extraction (quantitative method), dye penetration (qualitative method) and fluid filtration (quantitative method), in Class V composite resin restorations with a total-etch and a self-etch adhesive from one manufacturer. The evaluation of microleakage is performed by different methods, such as air pressure, bacterial assessment, radioisotope studies, scanning electron microscopy, chemical identifiers, electrochemical studies, and measurement of dye penetration $[11,22,23]$. Some studies have reported that different methods of microleakage evaluation do not differ in the final results $[19,24]$. To compare the average microleakage in Class $\mathrm{V}$ composite restorations, totaletch and self-etch adhesives were used such as previous studies [14-18]. Regarding the trend toward simplification, self-etch adhesives that combine the steps of etching, priming and bonding into one solution have become common. These self-etch, seventh-generation adhesives also called all-in-one adhesives. All-in-one adhesives act as semi permeable membranes, consequential a hydrolytic degradation of the resin-dentin interface [2]. Comparison of average microleakage in total-etch adhesive (Opti Bond Solo Plus) and self-etch adhesive (Optibond All-in-One) based on dye extraction and dye penetration methods indicated that the microleakage of both adhesives was not significantly different. Similarly to our result, Brackett et al. also used dye penetration for the microleakage in dentin margins and the results were indicated that there were no significant difference between self-etch adhesives and total-etch adhesive [15,17]. The adhesives in the current study included an etch-and-rinse
Table 2. Spearman's rho and Pearson results for the correlation between three methods of microleakage tests in experimental groups.

\begin{tabular}{|c|c|c|}
\hline $\begin{array}{l}\text { Method of microleakage } \\
\text { assessment }\end{array}$ & $\begin{array}{l}\text { Correlation } \\
\text { coefficient }\end{array}$ & P-value \\
\hline $\begin{array}{l}\text { Dye extraction with Dye } \\
\text { penetration }\end{array}$ & ${ }^{* *} \mathrm{SR}=0.048$ & $\mathrm{P}=0.824$ \\
\hline $\begin{array}{l}\text { Dye extraction with } \\
\text { Fluid-Filtration }\end{array}$ & ${ }^{*} \mathrm{SR}=0.102$ & $P=0.637$ \\
\hline $\begin{array}{l}\text { Dye penetration with } \\
\text { Fluid-Filtration }\end{array}$ & ${ }^{*} \mathrm{PR}=0.165$ & $\mathrm{P}=0.442$ \\
\hline
\end{tabular}

${ }^{*}$ Pearson correlation $=\mathrm{PR} ;{ }^{* *}$ Spearman correlation $=\mathrm{SR}$.

one-bottle system and a mild self-etch adhesive system; both are different in the hybrid layer formation and bonding mechanism. The demineralization of dentin and enamel in mild self-etch adhesives occur using acidic primers, so that some hydroxyapatite crystals exposed to acidic monomers remain around collagen fibrils in dentin. It is suggested that these remaining crystals have a chemical reaction with functional monomers and can prevent marginal microleakage $[6,25]$. Some researchers have shown differences in the sealing ability of restoration margins between these adhesives [26,27]. The results of the current study are consistent with studies carried out by Mitsui and others [26] and Pradelle and others [27]; both researchers stated that etch-and-rinse and self-etch systems do not differ in dentin margin microleakage. In fluid filtration method of this study, the microleakage of self-etch adhesive was more significantly than total-etch adhesive. In contrast of our finding, it was indicated that Xeno III self-etch adhesive had less leakage than Prime $\&$ Bond NT total-etch adhesive using fluid filtration [16]. This difference may be referred to the different self-etch and total-etch adhesives used in these studies and the laboratory assembly. Incomplete bonded restorations may produce changes in fluid flow and microleakage [28]. In the present study, more microleakage was observed in the self-etch adhesive than in the total-etch adhesive that is in agreement with those of Loguercio et al. study [29]. They concluded that the higher marginal leakage in the one-step self-etch adhesives may have been due to the inferior etching pattern of these systems. The $\mathrm{pH}$ of OSP and $\mathrm{OA}$ is 2.1 and 2.5, respectively [30]. The higher acidic $\mathrm{pH}$ for OA could justify the higher microleakage values. Some studies have demonstrated that pretreatment using $37 \%$ phosphoric acid can improve bonding quality $[31,32]$. One explanation for microleakage is degree of conversion that is not occurred completely in self-etch adhesives due to the existence of water and more hydrophilic monomers in their contents [33]. The hydrophilicity, functionality and size of monomers and filler content in dentin adhesives affected the water sorption, solubility, crosslink density and degree of conversion [33,34]. The 
experimental self-etch adhesive containing GDM monomer and filler showed higher property in comparison of total-etch adhesive, indicating higher crosslink density accompanied by a probably in- crease the degree of conversion in the polymer network structure. For some previous studies $[14,15,17,35,36]$ only dye penetration method was used to assess the microleakage of composite restorations. In the present study, like one previous study to evaluate the correlations among the three methods of microleakage assessment, fluid filtration method was defined as the control group and the correlations of the two other methods were assessed by it [19]. Therefore, the study was not indicated any significant correlations between the qualitative method (dye penetration) and quantitative methods (fluid filtration and dye extraction) like the past paper [21] but there was a positive correlation between them. This finding may be due the different test set-up and separate samples prepared for each microleakage assessment method. Additionally it is advisable to use dye extraction methods instead of fluid filtration since dye extraction gave the same results as fluid filtration but saved much laboratory time. In the future, it would be advisable to assess the sealing ability different adhesives with various methods and handling techniques for a long time and even in a situ study.

With the limitations of this study, it can be concluded that: Self-etch adhesive showed variously behave in different methods of microleakage assessment and proved more microleakage than total-etch adhesive in this short time evaluation. There were no significant correlations between different methods of microleakage evaluation.

\section{ACKNOWLEDGEMENTS}

The authors would like to thank the research council of the Mashhad University of Medical Sciences which financially supported this study (protocol code 88455, Dental student thesis 2448).

\section{REFERENCES}

[1] Hegde, M.N., Vyapaka, P. and Shetty, S. (2009) A comparative evaluation of microleakage of three different newer direct composite resins using a self etching primer in class V cavities: An in vitro study. Journal of Conservative Dentistry, 12, 160-163. doi:10.4103/0972-0707.58340

[2] Moosavi, H., Moazzami, S.M., Loh, S. and Salari, S. (2010) Microleakage evaluation of core buildup composite resins with total-etch and self-etch adhesive systems. Journal of Contemporary Dental Practice, 11, e009-e016.

[3] Hashimoto, M., Ohno, H., Kaga, M., Endo, K., Sano, H. and Oguchi, H. (2000) In vivo degradation of resin-dentin bonds in humans over 1 to 3 years. Journal of Dental Research, 79, 1385-1391. doi: $10.1177 / 00220345000790060601$
[4] De Munck, J., Van Meerbeek, B., Yoshida, Y., Inoue, S., Vargas, M., Suzuki, K., Lambrechts, P. and Vanherle, G. (2003) Four-year water degradation of total-etch adhesives bonded to dentin. Journal of Dental Research, 82, 136-140. doi:10.1177/154405910308200212

[5] Ermis, R.B., Van Landuyt, K.L., Cardoso, M.V., De Munck, J., Van Meerbeek, B. and Peumans, M. (2012) Clinical effectiveness of a one-step self-etch adhesive in non-carious cervical lesions at 2 years. Clinical Oral Investigations, 16, 889-897. doi:10.1007/s00784-011-0565-4

[6] Van Meerbeek, B., De Munck, J., Yoshida, Y., Inoue, S., Vargas, M., Vijay, P., Van Landuyt, K., Lambrechts, P. and Vanherle, G. (2003) Buonocore memorial lecture. Adhesion to enamel and dentin: Current status and future challenges. Operative Dentistry, 28, 215-235.

[7] Wang, Y. and Spencer, P. (2005) Continuing etching of an all-in-one adhesive in wet dentin tubules. Journal of Dental Research, 84, 350-354. doi:10.1177/154405910508400411

[8] Van Landuyt, K.L., Mine, A., De Munck, J., Jaecques, S., Peumans, M., Lambrechts, P. and Van Meerbeek, B. (2009) Are one-step adhesives easier to use and better performing? Multifactorial assessment of contemporary one-step self-etching adhesives. Journal of Adhesive Dentistry, 11, 175-190.

[9] Bradna, P., Vrbova, R., Dudek, M., Roubickova, A. and Housova, D. (2008) Comparison of bonding performance of self-etching and etch-and-rinse adhesives on human dentin using reliability analysis. Journal of Adhesive Dentistry, 10, 423-429.

[10] Sadeghi, M. (2009) Influence of flowable materials on microleakage of nanofilled and hybrid class II composite restorations with LED and QTH LCUs. Indian Journal of Dental Research, 20, 159-163. doi:10.4103/0970-9290.52891

[11] Swift Jr., E.J., Triolo Jr., P.T., Barkmeier, W.W., Bird, J.L. and Bounds, S.J. (1996) Effect of low-viscosity resins on the performance of dental adhesives. American Journal of Dentistry, 9, 100-104.

[12] Unlu, N., Krakaya, S., Ozer, F. and Say, E. (2003) Reducing microleakage in composite resin restorations: An in vitro study. European Journal of Prosthodontic Restorative Dentistry, 11, 171-175.

[13] Manuja, N. and Nagpal, R. (2012) Resin-tooth interfacial morphology and sealing ability of one-step self-etch adhesives: Microleakage and SEM study. Microscopy Research and Technique, 75, 903-909. doi:10.1002/jemt.22011

[14] Koliniotou-Koumpia, E., Dionysopoulos, P. and Koumpia, E. (2004) In vitro evaluation of microleakage from composites with new dentin adhesives. Journal of Oral Rehabilitation, 31, 1014-1022. doi:10.1111/j.1365-2842.2004.01323.x

[15] Bracket, W.W., Haisch, L.D., Pearce, M.G. and Brackett, M.G. (2004) Microleakage of Class V resin composite restorations placed with self-etching adhesives. Journal of Prosthetic Dentistry, 91, 42-45. doi:10.1016/j.prosdent.2003.10.003 
[16] Gregoire, G., Guignes, P.H. and Millas, A. (2005) Effect of self-etching adhesives and dentin permeability in a fluid flow model. Journal of Prosthetic Dentistry, 93, 5663. doi:10.1016/i.prosdent.2004.10.008

[17] Brackett, M.G., Brackett, W.W. and Haisch, L.D. (2006) Microleakage of Class V resin composites placed using self-etching resins: Effect of prior enamel etching. Quintessence International, 37, 109-113.

[18] Deliperi, S., Bardwell, D.N. and Wegley, C. (2007) Restoration interface microleakage using one total-etch and three self-etch adhesives. Operative Dentistry, 32, 179184. doi:10.2341/06-54

[19] Camps, J. and Pashley, D. (2003) Reliability of the dye penetration studies. Journal of Endodontic, 29, 595-599. doi:10.1097/00004770-200309000-00012

[20] De Gee, A.J., WU, M.K. and Wesselink, P.R. (1994) Sealing properties of Ketac-Endo glass ionomer cement and $\mathrm{AH} 26$ root canal sealers. International Endodontic Journal, 27, 239-244. doi:10.1111/j.1365-2591.1994.tb00262.x

[21] Pommel, L., Jacquot, B. and Camps, J. (2001) Lack of correlation among three methods for evaluation of apical leakage. Journal of Endodontics, 27, 347-350. doi:10.1097/00004770-200105000-00010

[22] Leevailoj, C., Cochran, A., Matis, B.A., Moore, B.K. and Platt, J.A. (2001) Microleakage of posterior packable resin compositeswith and without flowable liners. Operative Dentistry, 26, 302-307.

[23] Jain, P. and Belcher, M. (2000) Microleakage of Class II resin based composite restorations with flowable composite in the proximal box. American Journal of Dentistry, 13, 235-238.

[24] Moosavi, H., Moghaddas, M.J., Ghoddusi, J. and Rajabi, O. (2010) Effects of two antioxidants on the microleakage of resin-based composite restorations after nonvital bleaching. The Journal of Contemporary Dental Practice, 11, E033-E040.

[25] Breschi, L., Mazzoni, A., Ruggeri, A., Cadenaro, M., DiLenarda, R. and De Stefano Dorigo, E. (2008) Dental adhesion review: Aging and stability of the bonded interface. Dental Materials, 24, 90-101. doi:10.1016/j.dental.2007.02.009

[26] Mitsui, F.H., Bedran-de-Castro, A.K., Ritter, A.V., Cardoso, P.E. and Pimenta, L.A. (2003) Influence of load cycling onmarginal microleakage with two self-etching and two one-bottle dentin adhesive systems in dentin. Journal of Adhesive Dentistry, 5, 209-216.
[27] Pradelle-Plasse, N., Wenger, F., Picard, B. and Colon, P. (2004) Evaluation of microleakage of composite resin restorationsby an electrochemical technique: The impedance methodology. Dental Materials, 20, 425-434. doi:10.1016/j.dental.2003.06.003

[28] Vaidyanathan, T.K. and Vaidyanathan, J. (2009) Recent advances in the theory and mechanism of adhesive resin bonding to dentin: A critical review. Journal of Biomedical Materials Research Part B: Applied Biomaterials, 88, 558-578. doi:10.1002/jbm.b.31253

[29] Loguercio, A.D., Bittencourt, D.D., Baratieri, L.N. and Reis, A. (2007) A 36-month evaluation of self-etch and etch-and-rinse adhesives in non-carious cervical lesions. The Journal of the American Dental Association, 138, 507-514.

[30] Khoroushi, M. and Aghelinejad, S. (2011) Effect of postbleaching application of an antioxidant on enamel bond strength of three different adhesives. Medicina Oral, $\mathrm{Pa}$ tología Oral y Cirugía Bucal, 16, e990-e996. doi:10.4317/medoral.17127

[31] Kubo, S., Kawasaki, K., Yokota, H. and Hayashi, Y. (2006) Five-year clinical evaluation of two adhesive systems in non-carious cervical lesions. Journal of Dentistry, 34, 97-105. doi:10.1016/j.jdent.2005.04.003

[32] Peumans, M., De Munck, J., Van Landuyt, K., Lambrechts, P. and Van Meerbeek, B. (2007) Five-year clinical effectiveness of a two-step self-etching adhesive. Journal of Adhesive Dentistry, 9, 7-10.

[33] Park, J., Eslick, J., Ye, Q., Misra, A. and Spencer, P. (2011) The influence of chemical structure on the properties in methacrylate-based dentin adhesives. Dental Materials, 27, 1086-1093. doi:10.1016/j.dental.2011.07.011

[34] Itoh, S., Nakajima, M., Hosaka, K., Okuma, M., Takahashi, M., Shinoda, Y., Seki, N., Ikeda, M., Kishikawa, R., Foxton, R.M. and Tagami, J. (2010) Dentin bond durability and water sorption/solubility of one-step self-etch adhesives. Dental Materials Journal, 29, 623-630. doi:10.4012/dmj.2010-028

[35] Manhart, J., Yan Chen, H., Mehl, A., Weber, K. and Hichel, R. (2001) Marginal quality and microleakage of adhesive Class V restorations. Journal of Dentistry, 29, 123-130. doi:10.1016/S0300-5712(00)00066-X

[36] Yazici, A.R., Baseren, M. and Dayangac, B. (2002) The effect of current-generation bonding systems on microleakage of resin composite restorations. Quintessence International, 33, 763-769. 